\title{
A INVENÇÃO BIBLIOGRÁFICA DA ARTE NA MODERNIDADE: NOTAS HISTÓRICAS SOBRE A ORGANIZAÇÃO DO CONHECIMENTO ARTÍSTICO NO SÉCULO XVI
}

\author{
LA INVENCIÓN BIBLIOGRÁFICA DEL ARTE EN LA \\ MODERNIDAD: NOTAS HISTÓRICAS SOBRE LA \\ ORGANIZACIÓN DEL CONOCIMIENTO ARTÍSTICO EN \\ EL SIGLO XVI
}

Giulia Crippa $^{a}$

\begin{abstract}
RESUMO
Introdução: Propomos uma discussão sobre dois textos de natureza bibliográfica do século XVI, mais especificamente o quarto capítulo da ldea del tempio della pittura, de Giovan Paolo Lomazzo (publicado pela primeira vez em 1591), dedicado aos "antigos e modernos escritores de arte" (Lomazzo, 1971, p. 34) e o capítulo dedicado aos "Preceitos de pintura transmitidos pelos antigos e modernos" de Antonio Possevino, de seu Tractatio de Poesia et pintura ethnica, humana et fabulosa collata cum vera, honesta et sacra (1595). Trata-se de fontes históricas que permitem observar alguns aspectos da organização do conhecimento na arte quando esta começa a ser identificada como área com suas especificidades. Objetivos: Entender as escolhas da literatura sobre arte que estabeleceu as bases e demarcou as fronteiras de uma área de conhecimento chamado Arte. Ambos os autores devem ser considerados, além do bem mais conhecido Vasari, como personalidades que iniciaram a elaborar abordagens sistemáticas aos livros de arte, desenhando um campo de conhecimento através da compilação de bibliografias, de certa maneira uma abordagem inovadora nessa área do conhecimento na época, que se chamou de Arte. Metodologia: A abordagem metodológica desse estudo é histórica. $\mathrm{O}$ estudo das fontes originais combina-se com a revisão da literatura, pesquisando sobre que configuração do campo do conhecimento foi esboçada pelos autores e como determinou o desenvolvimento dos estudos sobre arte. Resultados: Os autores apresentam um repertório bibliográfico que aborda as questões de uma área em formação, a da Arte, através de perspectivas comuns, utilizando fontes antigas e modernas e, ao mesmo tempo, cada um refletindo interesses distintos. Lomazzo apresenta uma preocupação de natureza prática e Possevino de natureza mais moral. Conclusões: O conhecimento sobre a natureza do campo da arte, na medida em que ele constitui suas bases bibliográficas em registros textuais e visuais,
\end{abstract}

\footnotetext{
a Doutora em História Social - Universidade de São Paulo, Docente em Ciência da Informação Universidade de São Paulo. E-mail: giuliac@ffclrp.usp.br.
} 
oferece uma rica seara de estudos para o campo informacional, apresentando-se como peculiar em relação ao tratamento de seus documentos desde sua configuração inicial.

Descritores: Bibliografia Histórica. Arte. Giovan Paolo Lomazzo. Antonio Possevino.

\section{INTRODUÇÃO}

Objetivo desse artigo é analisar dois textos da segunda metade do século $\mathrm{XVI}$, o quarto capítulo da Idea del tempio della pittura, de autoria de Giovan Paolo Lomazzo, publicado em 1591, e os "Preceitos de pintura legados pelos antigos e pelos modernos", de Antonio Possevino, parte de seu Tractatio de Poesi et pintura ethnica, humana et fabulosa collata cum vera, honesta et sacra, publicado em 1595. Pretendemos oferecer uma leitura desses escritos através da perspectiva da organização do conhecimento (daqui em diante: KO, do inglês Knowledge Organization).

Com efeito, sentimos a necessidade de uma discussão mais aprimorada em termos de estudos críticos da KO no campo da Arte. Na medida em que se observa que a tradição se concentra, desde os primórdios, quando se manifesta um primeiro núcleo de materiais que permitem falar em campo de conhecimento, na concepção estética através da (re)produção das obras sem que haja uma distinção clara entre essas reproduções (em formato de livro uma "documentação" visual de obras) e a produção textual e na medida em que esta tradição é destinada a se manter ao longo do estabelecimento, cada vez mais formal, não somente de um campo de conhecimento, mas de um sistema autônomo, a abordagem de fontes históricas fornece ferramentas para 0 entendimento de suas formas de ordenamento. Pouco espaço foi dedicado ao estudo de como se formaram índices e repertórios enquanto produção propriamente bibliográfica, ligada ao livro como portador de signos verbais, ao longo do tempo. Isto, porém, não se caracteriza como uma falta de interesse em relação à KO. Muito pelo contrário: de fato, a História da Arte e sua Historiografia aparentam ter sempre se orientado, como interesse primário, para fontes que 
revelam, de maneira privilegiada, princípios estéticos e formais, portanto para as fontes visuais.

Em outras palavras, objetos como pinturas, esculturas e suas reproduções (inicialmente, como desenhos, depois como gravuras até se chegar às reproduções fotográficas) se encontram no cerne do estudo da arte. Os objetos e suas reproduções representam o repertório a partir do qual toda a reflexão artística tende a se desenvolver. Tais objetos são suas fontes principais, centralizando a atenção e levando à constituição das peculiaridades do sistema da arte.

Isso significa que os produtos artísticos, desde os primeiros tempos de constituição do campo da arte (que, como veremos, se coloca justamente por volta do século XVI) são, dentro do próprio campo, ao mesmo tempo monumentos e documentos. A ordem e a catalogação das obras de arte e de suas reproduções, voltada para apresentação das obras, está no cerne das preocupações de natureza bibliográfica, bem mais do que catálogos de instituições como bibliotecas enquanto instrumentos usados para descrição com finalidades de localização dos livros, que aparentam adquirir um interesse bem mais relativo, se comparado ao que acontece em outros campos de conhecimento, para os quais os livros impressos destacam-se como fontes privilegiadas ou até únicas. Nesse artigo, parte de uma pesquisa mais ampla dedicada a questões de colecionismo ao longo do tempo, buscamos ilustrar de que maneira esta prática da KO se enraíza em uma época em que um campo chamado artístico aparece no desenho incipiente de seu formato de maneira bastante específica.

Autores preocupados com a crítica e a teoria da arte ao longo da história do campo de conhecimento da Arte, como Blunt (1966) e Venturi (1966), mostram com clareza como a "arquitetura" desse campo vem se constituindo durante o Renascimento. É durante esta época que encontramos os elementos constitutivos de uma disciplina que, aos poucos passa a ser definida História da Arte, explicitada de maneira claramente diferente dos registros escritos anteriormente produzidos. Nesse sentido, consideramos que uma reflexão acerca dessas primeiras afirmações de um campo em formação, o da Arte, 
durante o Renascimento, se torna importante na ótica do entendimento de como e porquê esse campo desenvolveu suas próprias práticas de organização e representação documentária até alcançar o status de sistema no século XVIII (STRASSOLDO, 2010): o sistema da Arte criou suas próprias regras e estabeleceu seus próprios atores e analisar as fontes de sua fundação pode ajudar a entender melhor seus mecanismos e suas direções presentes.

\section{A RELAÇÃO ARTE/DOCUMENTO}

A prática bibliográfica no campo da história da arte oscila, a nosso ver, entre duas dimensões, uma metodológica e a outra aplicada. Uma tradição antiga que, pelo menos na cultura ocidental, coincide com o esforço enciclopédico-taxonômico inscrito nas primeiras divisões do pensamento clássico, passando pelas cosmologias intuitivas e as summae do conhecimento medieval, os teatros da memória e a ars combinatoria renascentista (CRIPPA, 2007), as árvores do conhecimento do século XVIII (DARNTON, 2001) e, em seguida, mais especificamente, com a modernidade, as enciclopédias iluministas, até chegar aos modelos visuais do Bilderatlas de Warburg (2012) e do "museu imaginário" de Malraux (1994), um "armazém" ideal a partir do qual se poderia atingir amplamente ideias, conceitos e imagens que, depois de separados de seu contexto originário, através da operação fotográfica, são recolocados em uma nova sequência. É a esta complexidade metodológica que os artistas, a partir de meados do século XX, seguindo a tradição, olham, buscando renova-la em suas práticas, conforme o momento, o lugar, os instrumentos técnicos dos quais dispõem e de seus objetivos. Trata-se de uma forma de atualização metodológica através da prática.

Esta oscilação revela que, antes de se tornar práxis, o gesto bibliográfico na arte é ligado tanto ao discurso sobre arte como às instituições que a preservam e expõem. A questão da exposição é de fundamental importância, na discussão sobre arte, na medida em que ela se configura através de práticas narrativas ligadas a este ato desde os primórdios de sua existência (HASKELL, 
2002) Selecionar, catalogar e expor são todas ações museológicas quotidianas que procuram ordenar o patrimônio cultural, mas, ao mesmo tempo, gestos autoritários que decidem quem e o que deve ser lembrado e quem esquecido. Por isso, na maioria dos casos, os artistas que operam com/sobre o arquivo como paradigma, metáfora ou medium, se engajam para subverter os métodos tradicionais de classificação e realizar contra-modelos de organização que, às vezes, estão bem longe de ser sistemas ordenados. Aqui se desenvolve uma dialética entre a arte que se coloca "fora" das regras e a ideia de arquivo, fortemente atrelada à necessidade de regras e formalidade.

Alguns historiadores da arte e curadores se preocupam com a questão da memória, da história e das alternativas às narrativas oficiais, considerando não o documento/obra individual, mas o arquivo como ponto focal (FOSTER, 2004).

Em 1926, Walter Benjamin elaborou uma reflexão sobre a relação entre a obra de arte e o documento em um breve texto intitulado '13 teses contra os esnobes', publicado em 1928 em Rua de mão única, seu livro de aforismos, brincadeiras e sonhos, como anunciou ao amigo Scholem nos primeiros estágios de sua concepção (EILAND; JENNINGS, 2016, p. 198). Ele listou em uma coluna à esquerda 13 propriedades que atribuiu às obras de arte e, à direita, um número correspondente de qualidades atribuídas ao documento. Essa distinção quase absoluta entre obra de arte e documento não foi a última palavra de Benjamin sobre o tema. Em dois ensaios datados poucos anos depois, o autor claramente atribui um papel subversivo aos documentos produzidos na arte de vanguarda e na literatura.

Se os documentos constroem, acidentalmente ou deliberadamente, traços materiais de várias naturezas que podem ser utilizados com finalidades comprobatórias, de educação, ou de registro legal, os monumentos, em contraste, são tradicionalmente entendidos com elementos intencionais através dos quais o passado é rememorado.

Michel Foucault relaciona documentos e monumentos em uma passagem de Arqueologia do saber (1994). Na medida em que ele resenha, na introdução de seu livro, os desenvolvimentos recentes relativos às pesquisas no campo das humanidades, Foucault aponta que para os historiadores uma questão central é 
a reavaliação do uso e da definição de documento, que "não é mais para a história um material inerte através do qual reconstituir o que os homens fizeram, ou disseram, os eventos dos quais somente os vestígios permanecem" (FOUCAULT, 1994, p. 10). Pelo contrário, a história

alterou sua posição em relação ao documento: escolheu, como seu ofício primário, não a interpretação do documento, nem a tentativa de decidir se esse fala a verdade ou qual é seu valor expressivo mas, sim, trabalha-lo do interior e desenvolve-lo: a história, agora, organiza o documento, o divide, distribui, ordena, arranja em níveis, estabelece séries. (FOUCAULT, 1994, p. 10)

Poucas linhas abaixo, conclui:

a história, em sua forma tradicional, escolheu 'memorizar' os monumentos do passado, transformando-os em documentos [...] Hoje, a história é aquela que transforma documentos em monumentos. (FOUCAULT, 1994, p. 11)

São afirmações que, de alguma maneira, se entrelaçam com os resultados da escola da 'crítica do documento' ligada à revista Les Annales, fundada por Marc Bloch, Lucien Febvre e Fernand Braudel em 1929.

Em Apologie pour l'histoire ou le métier d'historien de Marc Bloch (2015), o autor atribui um peso equivalente aos registros escritos (memórias, minutas e atas de encontros oficiais) voluntariamente transmitidas e àquelas marcas materiais involuntárias (como os achados arqueológicos, ou as marcas das atividades quotidianas) deixadas pelo passado. Ambos os tipos de documentos requerem um exame por parte dos historiadores com renovado ceticismo, além da simples questão de verdadeiro ou falso. Bloch explica que é necessário ler nas entrelinhas dos registros escritos e desconstruir seu discurso oficial, bem como é necessário ter clareza que as marcas materiais involuntárias podem funcionar como provas somente se soubermos colocar as questões certas.

Bloch e os historiadores dos Annales criticavam a visão positivista que favorecia a história política e a confiança que se tinha nos arquivos oficiais, produzidos pelo Estado. Ao lado da abordagem crítica e da ampliação da ideia de documento, a escola dos Annales considerava necessária a abertura da história às ciências sociais. Permitindo aos historiadores se deslocar além de suas fronteiras disciplinares, o escrutínio historiográfico da produção e 
interpretação dos documentos levava a uma reflexão mais ampla sobre os métodos de produção do conhecimento.

Em 1970, Michel de Certeau ampliou a reflexão sobre documento no contexto, no âmbito do que passa a ser chamada nouvelle histoire, voltando a atenção dos documentos usados pelos historiadores para a atividade dos próprios historiadores. Em uma passagem de A escrita da História (1982), e com um tom claramente anti-autoritário, De Certeau aponta para a qualidade institucional da história enquanto disciplina. Um 'documento' nunca é encontrado de maneira acidental. Na realidade, é sempre conscientemente construído como tal pelo historiador em sua prática:

$\mathrm{Na}$ história tudo começa com o gesto de separar, de juntar, de transformar certos objetos classificados em 'documentos'. Essa nova distribuição cultural é a primeira tarefa. $\mathrm{Na}$ verdade, consiste em produzir tais documentos pelos atos de copiar, transcrever, ou fotografar esses objetos, mudando ao mesmo tempo seu locus e seu status. (DE CERTEAU, 1982, p. 80)

Ainda, vale lembrar o que escreve Jacques Le Goff

O documento é um monumento. É o resultado do esforço realizado pelas sociedades históricas para impor, voluntaria ou involuntariamente, uma determinada imagem de si mesmas ao futuro. Não existe documento verdadeiro. Todo documento é uma mentira. É tarefa do historiador desconstruir, demolir essa montagem, desestruturar essa construção e analisar as condições de produção desses documentos-monumentos. (LE GOFF, 1978, p. 80)

A arte, como campo do conhecimento, desde seus primeiros momentos atua em relação aos produtos bibliográficos que o desenham, através de um tratamento bastante específico: a história da arte - enquanto disciplina histórica - se fundamenta em fontes primárias, seus "documentos", de natureza prioritariamente não-verbal, privilegiando imagens em detrimento da textualidade nesses "fazeres bibliográficos". Com efeito, a própria produção de "documentos" reunidos em livros - como desenhos ou gravuras, quando se trata de ilustrar, por exemplo, edificações arquitetônicas, esculturas ou, até, de reproduzir pinturas em nossa percepção "oscilam" entre monumento/documento. 
Observe-se como a gravura, tratando-se de uma forma de reprodução técnica cujos resultados sempre apresentam alguma diferença, ainda que em grau mínimo, é, ao mesmo tempo, um produto artístico e um registro de um outro artefato, derrubando uma demarcação clara entre obra de arte e reprodução por gravuras nos livros.

Dessa maneira, a constituição do campo da história da arte se dá com base em uma abordagem muito peculiar, ou seja, a criação e o tratamento dado aos materiais bibliográficos. Temos, como exemplo evidente, os autores objeto de nosso estudo, que exatamente nesse sentido de seleção de materiais bibliográficos podem ser analisados: o primeiro, Lomazzo, é um pintor. Possui, portanto, uma perspectiva clara sobre a necessidade de oferecer exemplos para a prática. As suas escolhas bibliográficas oscilam, assim, entre livros que contêm unicamente imagens, tais como "coleções" de desenhos e gravuras, e livros que tratam de técnicas e artistas.

O segundo autor, Possevino, é um religioso bastante atuante na implementação ideológica da contrarreforma católica e bem conhecido por sua atuação bibliográfica, através da compilação de sua Bibliotheca Selecta. Ele oferece, em relação ao campo artístico, um espaço bem menor às publicações dedicadas às imagens, necessárias, em Lomazzo, para a formação específica do artista a partir de "modelos" anteriores. Possevino, por outro lado, erudito pensador da KO de sua época, fornece uma lista de livros "disciplinares", não necessariamente escritos por artistas, mas que determinam a função, o uso e a ortodoxia das imagens.

O século XVI é considerado o momento chave em que se originou esse novo campo do conhecimento chamado Arte, que mostra uma necessidade de possuir sua própria trajetória. Historicamente, isso tem sido relacionado ao livro mais conhecido de Giorgio Vasari (1986), pintor maneirista, arquiteto e autor de Le vite de' più eccellenti pittori, scultori, e architettori, cuja primeira edição foi publicada em 1550. Esse trabalho é considerado o primeiro dedicado exclusivamente à arte e aos artistas. De fato, é possível encontrar numerosas referências, na literatura antiga, a objetos, tais como pinturas, estatuas ou edificações, todas categorias que classificamos sob o termo de Arte. A maioria 
dessa tipologia de escritos que contém referência à arte continua desde a Antiguidade, atravessando a Idade Média ocidental, da qual sobrevivem relatos sobre as atividades de edificação por parte de alguns indivíduos, descrições anedóticas de lugares e manuais de técnicas de várias atividades artísticas, como Tosatti (2007) mostra de maneira clara. É neste momento que a arte passa a falar da arte, logo, a constituir uma dada episteme, ou seja, uma reflexão sobre uma teoria do conhecimento específica, o que demarca a noção de campo em seu engendramento.

Os textos sobre arte nos quais, porém, podemos identificar algo destinado a ser chamado "história da arte" pertencem ao Renascimento, e diferem claramente destes exemplos anteriores em pelo menos três elementos:

1) $\mathrm{Na}$ Antiguidade e na Idade Média, comentários sobre Arte estão sempre embutidos em relatos sobre outros assuntos, enquanto durante o Renascimento a arte se torna um assunto separado e autônomo.

2) Encontra-se uma tradição específica de autores sobre História da Arte desde o Renascimento até os dias atuais, enquanto isso não acontece quando nos voltamos para a Antiguidade.

3) O estabelecimento de uma das ideias estruturais da cultura europeia (que somente nas últimas décadas perdeu vigor), a da imagem cíclica formulada por Petrarca no século XIV - que afirma haver um "pico" de civilização na Antiguidade, seguido por um declínio e uma nova revitalização, conforme ele, no próprio século XIV - e retomada por Ghiberti no século XVI à cronologia da arte. Como Fernie (1996) explica, Ghiberti afirma que, como resultado da Cristandade, todas as estátuas e pinturas de nobreza e perfeição foram destruídas, e a própria arte desapareceu até que o talento de Giotto a revitalizou.

O livro de Vasari Le vite..., originariamente publicado em 1550 e, em edição revisada e expandida em 1568, é o primeiro texto extenso e consistente o suficiente, relativo às artes para ser definido como propriamente "histórico" em sua concepção. Existe, nesse sentido, um consenso entre os estudiosos, o de que foi Vasari o protagonista da construção das regras de base da história da arte enquanto disciplina, pelo menos nos moldes nos quais foi elaborada ao longo dos dois séculos seguintes. Os principais elementos de sua abordagem 
podem ser individualizados sob os títulos de connoisseurship e de "humanismo", ambos voltados para o reconhecimento do papel central da ideia de "génio".

Hoje em dia, uma releitura de Vasari não permite mais que seu tratado possa ser identificado com a História da Arte, principalmente porque o autor não se preocupa em momento nenhum com os contextos históricos e sociais em que se inserem os artistas e as obras por ele tratados. Vasari de fato, destaca os resultados alcançados por cada um deles utilizando, com frequência um registro ligado às anedotas, sem que essas se fundamentem em arquivos ou repertórios confiáveis. Ainda assim, ele abriu um caminho novo, ligado à alguns aspectos da evidência documentária (as obras como "documentos"), utilizando técnicas inéditas de connoisseurship.

É somente no século XVIII que a abordagem de Vasari em relação à História da Arte sofre alguma alteração, por mão de Johann Joachim Winkelmann que, de fato, escreveu uma História da Arte mais do que uma história dos artistas, modificando, assim, a impostação do Vasari.

Com a premissa que, como afirmamos, a História da Arte se fundamenta não somente nem principalmente em literatura mas, de maneira privilegiada, na materialidade (ou na representação) das obras de arte, fato permitido pelas características do conhecedor e enraizado em suas habilidades, podemos observar que as experiências atuais na KO no âmbito da arte (por exemplo, o Art \& Architecture Thesaurus - AAT -, projeto ligado à Fundação Getty, iniciado no final da década de 1970, ou o Iconoclass, um sistema de classificação criado na Holanda já na década de 1950) ainda desenham, descrevem e organizam a arte como um campo dentro do qual os objetos (sua representação/referência) e os escritos sobre arte não possuem uma distinção/separação hierárquica. Por isso, consideramos que esta peculiaridade merece um estudo mais aprofundado, e, na ótica de entender esse esquema peculiar da KO do campo, indagamos a maneira pela qual o próprio campo explicita a si próprio quando começa a se tornar um sistema autônomo, isso é, a partir do Renascimento.

Nossas inquietações enveredam pelos seguintes assuntos: o que acontece no desenho do campo enquanto resultado também de textos escritos, de livros? O que se pode dizer sobre a constituição de "mapas" bibliográficos de 
autores e títulos, considerando a tipologia dos materiais que constituem o campo de conhecimento da arte, bem no começo de sua trajetória e definição?

A arte designa um campo não científico, em que prevalecem as práticas e as técnicas de construção, e por isso tem sua lógica que os autores que escreveram sobre arte tenham privilegiado esse lado do conhecimento, como 0 fez Vasari. Por outro lado, como veremos nos textos de Lomazzo e de Possevino, uma outra perspectiva aparece dentro do campo, mais relacionada à discussão propriamente bibliográfica.

Sem adentrar no domínio teorético sobre bibliografia, gostaríamos de atrelar nossas afirmações à ideia de uma bibliografia enumerativa, como Stokes (1982) define aquela bibliografia cuja meta principal é de criar um documento sobre todos os materiais existentes, ou dos quais se tem conhecimento que existiram. Em uma perspectiva em que a bibliografia busca fornecer aos estudiosos ferramentas de trabalho, podemos focar nos autores que selecionamos para analisar em nosso artigo. Nossa metodologia consiste em trabalhar com os textos originais, para procurar entender as escolhas realizadas na literatura sobre arte que estabeleceram as fundações e demarcaram as fronteiras desse campo de conhecimento. $O$ estudo das fontes combina-se com as reflexões críticas da literatura existente, indagando que tipo de campo de conhecimento foi esboçado por esses autores.

\section{LOMAZZO}

Giovan Paolo Lomazzo (1538-1600) foi um pintor maneirista Lombardo que deslocou suas atividades da prática da Pintura para a teoria quando se tornou cego. Com efeito, um dos principais resultados das reflexões de Lomazzo, segundo Venturi (1966) foi exatamente a separação entre a produção artística e a teoria artística. No texto que aqui nos propomos a analisar, ele apresenta uma resenha bibliográfica que se estende da Antiguidade até a época a ele contemporânea. O quarto capítulo de sua Idea del tempio della pittura é uma breve bibliografia enumerativa que oferece uma lista de autores e títulos de livros, tanto impressos como manuscritos. A lista de Lomazzo oferece diversas tipologias de materiais, que compreendem textos manuscritos e impressos, bem 
como publicações de desenhos e gravuras. Acreditamos que isso mostra o nó central da discussão que necessita ser ampliada nas vertentes teóricas ligadas à KO: de alguma maneira a arte, desde sempre considerada o lugar onde peças únicas de arte visual e de arquitetura se destacam, é um campo no qual existe uma clara noção da importância de documentos não textual. Nesse sentido, a História da Arte se apresenta como a primeira disciplina não baseada somente em textos escritos desde seu começo.

Vamos, agora, olhar para o texto do Lomazzo.

Autores da Antiguidade: praticamente, todos os autores por ele listados foram perdidos. Existem, somente, como autores citados dentro da História Natural de Plínio o Velho, mas Lomazzo fala a respeito de suas obras como se fosse possível encontrá-los.

São eles:

1) Menecmo. No índice de Plinio: Menaechmo qui de toreutice ${ }^{1}$ scripsit.

2) Lisippo. Sobre ele, sempre Plínio utiliza como referência Duride de Samos (340-280 a.C), discípulo de Teofrasto - o qual é, de fato, uma das referências que Plínio utiliza em seu índice.

3) Pasitele. Nesse caso, Lomazzo confunde esse autor com Praxíteles, atribuindo-lhe 5 volumes sobre escultura. Plínio escreve: qui mirabilia opera scripsit sobre escultura e entre aqueles qui de pictura scripserunt. Ainda: qui et quinque voluminis scripsit nobilium operum in toto orbe.

4) Eufranore Istmio. Plínio o cita como autor sobre cores: volumina quoque composuit de symmetria et coloribus.

5) Antígono. Plínio afirma que escreveu sobre toreutica e qui volumina condidit sua arte.

6) Xenócrates. Plínio alega que Xenocrate Zenonis escreveu tanto sobre pintura como sobre escultura, Et de sua arte composuit volumina.

7) Apeles. Sobre esse artista, Plínio diz que voluminibus etiam editis, quae doctrinam eam continent e que Apellis discipulus Perseus, ad quem de hac arte scripsit.

1 Toreutica é a arte de trabalhar os metais com o cinzel e o martelo. 
Depois desses autores antigos, cujos trabalhos foram perdidos, Lomazzo lista uma série de referências sobre aritmética e geometria:

1) Alhazen Alí Muhammad ibn al Hasan ibn al Haytham - (Bássora, 965 Egypt 1039). Lomazzo explica que escreveu 7 livros, conhecidos desde o século XIII graças a uma tradução de um monge polonês, Vitellionis. Os 3 livros $D e$ aspectibus contês textos sobre a luz e o Opticae Thesaurus. Lomazzo provavelmente os conhecia de uma edição de Risner, que os publicou em Basel, em 1572.

2) Vitruvio é claro, é citado por Lomazzo

3) Caius Julius Iginus (60 a.C.-10 d.C.), que, supostamente, foi bibliotecário durante o império de Augusto e que escreveu sobre ótica.

4) Euclides. Lomazzo lista I quindici libri degli elementi. Não sabemos se se refere à edição traduzida por Cajano, publicada em Roma por Blado em 1545, ou à obra completa, publicada com o título Euclide, traduzida pelo famoso matemático Nicolau Tartaglia em Venice em 1565

5) Arquimedes (Opera, N. Tartaglia, Veneza 1543/Opera Nonnulla, tradução. Federico Commandino, Veneza, Manuzio, 1558)

6) Gemino, um astrônomo grego.

A essa Altura de sua enumeração, Lomazzo afirma que nada mais foi escrito depois desses autores. Nesse sentido, ele reflete plenamente a visão Renascentista de ciclos de apogeu e decadência, identificando, logo em seguida, os autores modernos sobre arte. Esse trecho é particularmente interessante, pois ele se refere tanto a livros impressos e manuscritos como a livros de esboços, com desenhos e gravuras. Na lista, são citados:

1) Donato Bramante, com um livro de desenhos feitos à mão, que é citado também pelo Vasari.

2) Bartolomeo Suardi (conhecido também como Bramantino), pintor de Milão, que escreveu vários livros sobre antiguidades que, porém, não foram publicados, diz Lomazzo.

3) Vincenzo Foppa, pintor lombardo, cujos textos Lomazzo alega ter visto, mas que foram perdidos. É, este, um autor não citado pelo Vasari. 
4) Baldassarre Petrucci (ou Peruzzi), artista maneirista. Lomazzo Ihe atribui a autoria de uma obra sobre arquitetura que, todavia, é conhecida por ter sido escrita por Sebastiano Serlio (I cinque libri dell'architettura).

5) Andrea Mantegna, com um livro que contém desenhos com explicações, um manuscrito que Lomazzo diz ter consultado na coleção de Andrea Gallarato, um nobre abade de Milão.

6) Bernardo Zenale, com um tratado sobre perspectiva, publicado em 1524 e perdido.

7) Bernardino Butinone, um colaborador de Zenale.

8) Marco da Siena, autor de um volume sobre Arquitetura - também perdido.

9) Leonardo da Vinci - um tratado sobre Anatomia. Lomazzo afirma tê-lo visto na coleção de Francesco Melzi, um aprendiz de Leonardo. O Mestre deixou para Melzi todos os seus livros em um testamento redigido em 1518. Lomazzo se refere a uma parte do Codex Urbinate, no qual o próprio Melzi reuniu os textos esparsos e os pensamentos de Leonardo, inclusive alguns retirados de fontes hoje perdidas. Lomazzo afirma que nenhum desses textos pode ser encontrado impresso, e que os manuscritos foram dados pelo filho de Melzi ao escultor do rei de Espanha, Pompeu Leoni. Mais tarde, foram de posse de Guido Mazenta, irmão do arquiteto e jurista Giovanni Ambrogi.

Depois dessa lista de manuscritos, Lomazzo oferece uma lista de livros impressos, de autoria de seus contemporâneos:

1) Leon Battista Alberti, De Pictura e, ainda mais relevante, na opinião de Lomazzo, o De Re Aedificatoria, 1450.

2) Pomponio Gaurico, De sculptura, Florença, 1504. Esse autor está presente, como veremos, também na lista de Possevino, porém não é um dos autores considerados pelo Vasari.

3) Luca da Borgo (conhecido como Pacioli), De divina proportione - Veneza, 1497 e 1509.

4) lacopo Barozzi (ou Vignola), Regola delli cinque ordini d'architettura (1562) e Le due Regole della prospettiva pratica (póstumo, 1583).

Lomazzo em seguida, expande seu mapeamento bibliográfico além das fronteiras italianas, listando autores estrangeiros que ele considera relevantes: 
1) Jan Steven van Calcar, autor of the planches of Vesalius' De Humani corporis fabrica. Interessante perceber, aqui, que são as gravuras que interessam, não o livro de estudos anatômicos de Vesalius enquanto obra "médica".

2) Albrecht Dürer, autor que não é citado pelo Vasari, mas que o Lomazzo apresenta por três obras sobre geometria: Unterweisung der Messung, Nuremberg, 1525, Institutiones Geometricae, traduzido para o latin por Joachim Camerarius, Lutece, 1532 e I geometrici elementi di Alberto Durero, publicado em 1537.

\section{POSSEVINO}

O jesuíta Antonio Possevino (1533-1611), autor da Bibliotheca Selecta, é considerado "o mais relevante bibliógrafo católico do século XVI" (CECCARELLI, 1993, p. 713).

Sua Bibliotheca Selecta oferece um modelo enciclopédico rigidamente delimitado, o da doutrina católica da Contrarreforma como delineada pelo Concílio de Trento. Esse modelo se torna instrumento de controle estrito aplicado à informação bibliográfica e à circulação de livros, voltado para a construção, "no plano documentário, de uma memória coletiva selecionada de acordo com um programa pedagógico específico" (BALSAMO, 2017, p. 55).

Assim como Lomazzo, Possevino também segue um procedimento cronológico em sua narrativa sobre Arte. Todavia, à diferença do primeiro, não cita os autores contidos na História Natural de Plínio como se tratasse de fontes disponíveis. Limita-se a citar o próprio Plínio, utilizando seus volumes XXIV e $X X V$ como fonte efetivamente disponível que providencia um relatório sobre boa parte das artes, técnicas e artistas da Antiguidade. Possevino escolhe fornecer referências bibliográficas somente quando as fontes podem ser efetivamente encontradas.

É o caso de Filostratus de Lemno, nascido no século II d.C., autor do volume Immagini, ou Icone, como explica Possevino. A obra pode ser encontrada em Grego, Latim e Francês, além de existir uma versão italiana, de Giovanni Andreozzi de Lucca, que, porém, destaca o Possevino, ainda não fora publicada. 
O nosso bibliógrafo explica que a tradução para o latim tinha sido realizada muitos anos antes, sendo publicada em Milão por Giovanni Castello já em 1521. Refere-se também à tradução francesa, realizada por Blaise de Vigenère.

Segue uma lista de autores e de obras: Albrecht Dürer e Pompônio Gaurico que, como vimos, também são repertoriados por Lomazzo; Pierre Gregoire, autor da Syntaxes artis mirabilis que, porém, sublinha Possevino, se encontra no Index librorum prohibitorum; Giulio Cesare Scaligero, que escreveu contra Cardano, acusado de ser um mago.

A partir desse momento, Possevino que, como dissemos, não é um artista, mas um erudito religioso e bibliógrafo, seleciona um conjunto de autores e de livros que não são dedicados às técnicas mas, sim, à moralidade na pintura e na escultura. Para todos esses livros, oferece um breve resumo:

1) Gregorio Comanini, um religioso lateranense, autor de I/ Figino, publicado em 1591, no qual Comanini discute a finalidade da pintura, se ela tem uma utilidade ou é somente um objeto de lazer e como utiliza-la entre os cristãos.

2) Giovan Battista Armenini, De' veri precetti della pittura, 1586, onde se discutem questões ligadas a como pintar lugares e pessoas. Possevino destaca o prefácio da obra, em que Armenini acusa aqueles artistas que escondem as "regras" da arte, de maneira que, sem regras explicadas, a aprendizagem se tornamais difícil e lenta. Em seu resumo, Possevino destaca as qualidades morais da arte e dos artistas em seu ofício.

3) Gabriele Paleotti, Discorso intorno alle imagini sacre e profane, Bologna, 1582. Possevino afirma que aquilo que o cardeal, "impulsionado pelo amor ardente para com sua diocese, escreveu em seu livro devoto sobre imagens é de tamanha importância que nenhum pintor jamais recusará sua leitura" (Possevino, 1971, p. 53).

4) Andrea Gilio, que escreveu e publicou um diálogo dedicado ao cardeal Alessandro Farnese (1564), em que aponta os erros e abusos cometidos pelos pintores nas obras históricas. Critica também Michelangelo por seu Juízo Final e outros artistas, explicando como devem ser realizadas as imagens sagradas.

5) Bartolomeo Ammannati, autor de uma carta aos Accademici del disegno (1582). 
Como podemos observar, Possevino oferece uma interpretação devocional dos textos figurativos de seu tempo. Vale a pena, aqui, destacar que a última parte de sua bibliografia sobre arte é dedicada aos danos morais provocados pela representação artística da nudez.

\section{CONSIDERAÇÕES FINAIS}

Os repertórios bibliográficos de Lomazzo e Possevino são exemplares: ambos usam fontes antigas, posicionando-se contra a crítica levantada pelo Vasari, que era contrário ao uso de autores como Plínio, Vitrúvio etc. Lomazzo e Possevino ampliam o conhecimento de autores que trabalharam longe dos círculos de Florença, o primeiro oferecendo um leque de publicações sobre livros e autores lombardos, enquanto Possevino, bastante envolvido com preocupações de cunho moral, procura autores que não produzem necessariamente arte mas, sim, que a discutem em uma perspectiva mais teorética, enquanto sensíveis aos ditados do Concílio de Trento (trata-se de autores como Gilio, Paleotti e Comanini). Interessante destacar que Possevino não insere, entre os autores o próprio Vasari.

Pode ser observado que Lomazzo, enquanto pintor, revela uma preocupação maior em relação ao fornecimento de recursos bibliográficos (impressos ou manuscritos) que podem ser utilizados diretamente pelos artistas para serem aplicados em seus trabalhos, como é o caso das obras sobre geometria ou perspectiva, bem como os livros de esboços e modelos.

Por outro lado, Possevino, enquanto bibliógrafo não diretamente envolvido na produção artística, expressa uma preocupação de cunho moral, acerca da arte, buscando autores que tratem do tema de um ponto de vista teórico, para estruturar o sentido dos objetos de arte, oferecendo títulos que se afastam do domínio das técnicas.

Com a premissa de que ambos os autores estão entre os pioneiros na compilação de bibliografias sobre Arte, podemos considera-los duas importantes peças que podem ajudar no estudo e entendimento, a ser desenvolvido, de como se constrói a KO quando se percorre a história do campo da Arte. 


\section{REFERÊNCIAS}

BALSAMO, L. La bibliografia: storia di una tradizione. Milano: Unicopli, 2017.

BENJAMIN, W. Rua de mão única. São Paulo: Brasiliense, 1995.

BLOCH, M. Apologia della storia. Alessandria: Falsopiano, 2015.

BLUNT, A. Le teorie artistiche in Italia: dal Rinascimento al Manierismo. Torino: Einaudi, 1966.

CECCARELLI, M. G. Antonio Possevino. In: SERRAI, A. Storia della bibliografia. Roma; Bulzoni, 1993. p. 711-760. vol. 4.

CRIPPA, G. Os "Lugares da memória": dispositivos ideológicos, esquemas tópicos e sistemas classificatórios. In: LARA, M. G. de; FUJINO, A.; NORONHA, D. P. Informação e contemporaneidade, p. 121-138. Recife: Nectar, 2007.

DARNTON, R. O grande massacre de gatos. Rio de Janeiro: Graal, 2001.

DE CERTEAU, M. A escrita da História. Rio de Janeiro: Forense, 1982.

EILAND, H.; JENNINGS, M. W. Walter Benjamin: una biografia critica. Torino: Einaudi, 2016.

FERNIE, E. Art history and its methods: a critical anthology. London: Phaidon, 1996.

FOSTER, H. An archival impulse. Princeton: MIT Press, 2004. p. 03-22.

FOUCAULT, M. L'archeologia del sapere. Milano: B.U.R., 1994.

HASKELL, F. Le musée éphémère: les maîtres anciens et l'essor des expositions. Paris: Gallimard, 2002.

LE GOFF, J. Documento/Monumento. In: Enciclopedia Einaudi. Torino: Einaudi, 1978. p. 39-48. v. 5.

LOMAZZO, G. P. Degli scrittori dell'arte antichi e moderni. In: BAROCCHI, Paola (Org.). Scritti d'arte del Cinquecento. Tomo I, p. 34-41. Milano-Napoli: Ricciardi, 1971.

MALRAUX, A. II museo dei musei. Milano: Leonardo, 1994. 
POSSEVINO, A. Quinam pingendi praecepta tradiderint antiqui et recentes. In: BAROCCHI, P. (Org.). Scritti d'arte del Cinquecento. Tomo I, p. 42-53. Milano-Napoli, Ricciardi, 1971.

STOKES, R. The function of bibliography. Aldershot: Gower, 1982.

STRASSOLDO, R. Da David a Saatchi: trattato di sociologia dell'arte contemporanea. Udine: Forum, 2010.

TOSATTI, S. B. Trattati medievali di tecniche artistiche. Milano: Jaca Book, 2007.

VASARI, G. Le vite dei più eccellenti pittori, scultori e architetti. Torino: Einaudi, 1986.

VENTURI, L. Storia della critica d'arte. Torino: Einaudi, 1966.

WARBURG, A. L’Atlas Mnémosyne. Paris: L'écarquillé/INHA, 2012.

\title{
THE BIBLIOGRAPHICAL INVENTION OF ART IN MODERNITY: HISTORICAL NOTES ON ARTISTIC KNOWLEDGE ORGANIZATION IN THE 16TH CENTURY
}

\begin{abstract}
Introduction: We propose a discussion on two writings of the 16th century of bibliographic nature, specifically the fourth chapter of the Idea del tempio della pittura by Giovan Paolo Lomazzo (first published in 1591), dedicated to "the ancient and modern writers of art" (Lomazzo, 1971, p. 34) and Antonio Possevino's chapter "Painting precepts transmitted by the ancients and the moderns", from his Tractatio de Poesia et pintura ethnica, humana et fabulosa collata cum vera, honesta et sacra (1595). Objective: to understand the choices in art literature that established the bases and marked the frontiers of an area of knowledge organization (KO) called Art as designed by Art History. Both the authors must be considered, beside the much more known Vasari, as authors which starts to elaborate systematic approaches to art books, designing an area of knowledge through the compilation of bibliographies, somehow a new approach in this new specific area of knowledge at the time that is called Art. Methodology: The methodological approach of the study is historical, combining sources studies with literature reflections, inquiring what kind of knowledge area was designed by these authors and how it determined the development of art studies. Results: Both the authors show a bibliographic repertoire focusing issues in the forming area of art through common perspectives, using ancient and modern sources and, at the same time, each one reflects different interests. Lomazzo shows a practical concern, while Possevino's concern is of a more moral nature. Conclusões: Knowledge on the nature of the area of Art, as it builds its bibliographic bases both in textual and visual
\end{abstract}

Inf. Inf., Londrina, v. 23, n. 2, p. 58 - 77, maio/ago. 2018.

http://www.uel.br/revistas/informacao/ 
records, offers a rich harvest for studies in the information field, as art presents a peculiar treatment of its documents since its original configuration.

Descriptors: Historical Bibliography; Art; Giovan Paolo Lomazzo; Antonio Possevino.

\title{
LA INVENCIÓN BIBLIOGRÁFICA DEL ARTE EN LA MODERNIDAD: NOTAS HISTÓRICAS SOBRE LA ORGANIZACIÓN DEL CONOCIMIENTO ARTÍSTICO EN EL SIGLO XVI
}

\begin{abstract}
RESUMEN
Introducción: Proponemos una discusión sobre dos textos de naturaleza bibliográfica del siglo XVI, más específicamente el cuarto capítulo de la Idea del tempio della pittura, de Giovan Paolo Lomazzo (publicado por la primera vez en 1591), dedicado a los "antiguos y modernos escritores de arte" (Lomazzo, 1971, p. 34) y el capítulo dedicado a los "preceptos de pintura transmitidos por los antiguos y modernos" de Antonio Possevino, de su Tractatio de Poesia et pintura ethnica, humana et fabulosa collata cum vera, honesta et sacra (1595). Se trata de fuentes históricas que nos permiten observar algunos aspectos de la organización de la concepción de arte cuando se trata de ser identificado como un área con sus especificidades. Objetivos: Entender las elecciones de la literatura sobre arte que estableció las bases y demarcó las fronteras de una área de conocimiento llamado Arte. Ambos autores deben ser considerados, además del bien más conocidos Vasari, como personalidades que iniciaron a elaborar enfoques sistemáticos a los libros de arte, dibujando un campo de conocimiento a través de la compilación de bibliografías, de cierta manera un enfoque innovador en esa nueva área específica en la época, que se llamó Arte. Metodología: El estudio de las fuentes originales se combina con la revisión de la literatura, investigando sobre qué configuración del área del conocimiento fue esbozada por los autores y cómo determinó el desarrollo de los estudios sobre arte. Resultados: Los autores presentan un repertorio bibliográfico que aborda las cuestiones de un campo en formación, el del Arte, a través de perspectivas comunes, utilizando fuentes antiguas y modernas $\mathrm{y}$, al mismo tiempo, cada uno reflejando intereses distintos. Lomazzo presenta una preocupación de naturaleza práctica y Possevino de naturaleza más moral. Conclusiones: El conocimiento sobre la naturaleza del área del arte, en la medida en que él constituye sus bases bibliográficas en registros textuales y visuales, ofrece una rica seña de estudios para el campo informacional, presentándose como peculiar en relación al tratamiento de sus documentos desde su concepción configuración inicial.
\end{abstract}

Descriptores: Bibliografía Histórica. Arte. Giovan Paolo Lomazzo. Antonio Possevino.

Recebido: 10.05 .2018

Aceito: 25.08 .2018

Inf. Inf., Londrina, v. 23, n. 2, p. 58 - 77, maio/ago. 2018.

http://www.uel.br/revistas/informacao/ 